\title{
Desarrollo político y económico en África: sesenta años de transformación
}

\section{María Ángeles Alaminos Hervás'}

Resumen: En el presente artículo analizamos la evolución del continente africano durante los últimos sesenta años, desde el momento de la descolonización y las independencias africanas, hasta la actualidad, centrándonos en las transformaciones más importantes experimentadas en el ámbito del desarrollo económico y político, con el objetivo de sentar las bases para una comprensión general de los principales procesos desarrollados en el continente en las últimas décadas. Con el objetivo de ofrecer una visión comprehensiva de las principales cuestiones políticas y económicas, se explicitan tanto las dinámicas internas como los intereses y las interacciones externas que subyacen en los procesos coloniales y poscoloniales. El artículo aborda dos grandes temas de los estudios africanos, la trayectoria política del Estado africano poscolonial y la economía política del desarrollo africano, antes de esbozar la reciente y progresiva rivalidad de las principales potencias por los recursos e influencia en el continente africano, y por último se procede a realizar unas conclusiones generales. La coyuntura actual en África, con protestas y movilizaciones multitudinarias de africanos que aspiran a generar cambios decisivos en sus países, muestra que es un momento clave para la reflexión y un punto de inflexión hacia una eventual transformación estructural del continente, no obstante los desafíos.

Palabras clave: África, Estado, desarrollo, democratización, política, economía

' Departamento de Estudios Internacionales. Universidad Loyola Andalucía. 
The evolution of the African continent and its transformation in the context of economic, social and political development sixty years after decolonisation and independence

\begin{abstract}
In this article we are going to analyse the evolution of the African continent during the last 60 years from decolonisation and independence to current times. We will focus on the most important transformations experienced in the economic and political development in order to prepare the foundations for a general understanding of the main processes developed on the continent during the last decades. The aim is to offer a comprehensive vision of the main political and economic questions, and so internal dynamics as well as external interests and influences which characterise colonial and post-colonial processes will be examined in detail. This article approaches two big African research topics, the political evolution of the post-colonial African state and the political economy of African development before moving on to sketch out the recent growing rivalry between the dominant powers over influence and resources, ending with some general conclusions. The current economic situation, marked my protests and mass mobilisations of Africans who aspire to generate decisive changes in their countries, indicate that despite the challenges, it is a key moment for reflection and a point of inflection towards an eventual structural transformation of the continent.
\end{abstract}

Key words: Africa, State, development, democratisation, politics, economy.
L'évolution du continent africain et sa transformation dans le domaine du développement économique, social et politique soixante ans après les indépendances africaines

Résumé: Dans cet article, nous allons analyser l'évolution du continent africain au cours des 60 dernières années, de la décolonisation et de l'indépendance à l'époque actuelle. Nous nous concentrerons sur les transformations les plus importantes vécues dans le développement économique et politique afin de préparer les bases d'une compréhension générale des principaux processus développés sur le continent au cours des dernières décennies. L'objectif est d'offrir une vision globale des principales questions politiques et économiques. Ainsi, les dynamiques internes ainsi que les intérêts et influences externes qui caractérisent les processus coloniaux ef postcoloniaux seront examinés en détail. Cet article aborde deux grands thèmes de recherche africains, l'évolution politique de l'État africain postcolonial et l'économie politique du développement africain, avant d'esquisser la récente rivalité croissante entre les puissances dominantes pour l'influence et les ressources, pour terminer par quelques conclusions générales. La situation économique actuelle, marquée par les mouvements et les mobilisations de masse des Africains qui aspirent à générer des changements décisifs dans leurs pays, indique que, malgré les défis, il s'agit $d$ 'un moment clé de réflexion et $d^{\prime}$ un point $d^{\prime}$ 'inflexion vers une éventuelle transformation structurelle du continent.

Mots clé: Afrique, État, développement, démocratisation, politique, économie. 


\section{Introducción}

En 2020 se conmemoraron los sesenta años de las independencias africanas, momento que parece idóneo para hacer un balance general sobre las principales transformaciones experimentadas por el continente, así como abordar algunos desafíos a los que debe enfrentarse África en la actualidad. La historia de los siglos XIX y XX es fundamental para aprehender el proceso de formación del Estado africano y para comprender los fenómenos acaecidos tras la independencia de los países.

Aunque 1960 es considerado "el año de África", debido al profuso número de países africanos que obtuvieron su independencia en ese año, en concreto diecisiete países de África subsahariana (catorce de ellos antiguas colonias francesas), el movimiento descolonizador comenzó en los años cincuenta, con la progresiva movilización y lucha por la liberación nacional de los países africanos. Si Libia fue el primer país en obtener la independencia en 1951, y Sudán y Ghana fueron los primeros países de África subsahariana en independizarse en 1956 y 1957 respectivamente, debemos recordar que la descolonización no se dio por terminada hasta la década de los años noventa. En 1994 se celebraron las primeras elecciones democráticas en Sudáfrica, las cuales pusieron fin al régimen de segregación racial del apartheid, culminando décadas de lucha contra el racismo y abriendo la puerta a un gobierno multirracial basado en la regla de la mayoría, bajo el liderazgo del primer presidente negro de Sudáfrica, Nelson Mandela.

Este momento de celebración y conmemoración del proceso de descolonización de África nos ofrece la oportunidad de analizar lo que han supuesto estos últimos sesenta años para el continente africano, en línea con la aproximación de este número especial de la Revista Fomento Social. Nos disponemos, pues, a abordar la evolución del continente africano y su transformación en el ámbito del desarrollo económico y político. La interrelación entre dichos ámbitos del desarrollo sienta las bases para la comprensión de las transformaciones de África en las últimas décadas.

No obstante, hemos de partir de la premisa de que realizar una valoración holística sobre el camino recorrido por el continente africano durante las últimas seis décadas reviste una gran dificultad, tanto por la diversidad e idiosincrasia de los distintos países y subregiones que lo conforman, como por la extensión del periodo histórico analizado. Es por ello que llevaremos a cabo en este artículo, desde la humildad, una aproximación general de algunos de los principales procesos políticos, económicos y sociales que han marcado el continente, teniendo siempre en cuenta que los contextos locales, nacionales, regionales e internacionales están 
en continuo movimiento y evolución, y que no hay respuestas únicas o unívocas a los principales desafíos que deben afrontar las sociedades africanas.

El objetivo central de este artículo será, por tanto, analizar las transformaciones más significativas con respecto al desarrollo económico, social y político de África durante los últimos sesenta años. En este sentido, con la ambición de ofrecer una visión crítica y comprehensiva de las principales cuestiones políticas y económicas, explicitaremos tanto las dinámicas internas como las interacciones y los intereses externos que subyacen en los procesos políticos coloniales y poscoloniales.

Dada la extensión del artículo y su aproximación, abordaremos la evolución del continente africano de forma general, aunque resaltamos aquí que en ningún caso podemos comprender el funcionamiento político y económico de África como un todo homogéneo, ya que no existe un sistema político o económico único que pueda adaptarse a todos los Estados africanos, sino que el continente es evidentemente diverso y heterogéneo, y en el caso de profundizar teórica y empíricamente, cada país africano debe estudiarse de manera específica y singular.

Por último, aunque el artículo presenta un enfoque abarcador de toda África, identificando elementos, factores y dinámicas relevantes a lo largo del periodo colonial y poscolonial, haremos hincapié en la política africana poscolonial, de manera particular en África subsahariana, teniendo siempre en cuenta que los africanos son agentes activos de su propio desarrollo, y que son las diferentes voces locales las protagonistas a la hora de narrar la historia y evolución del continente.

\section{Trayectoria política del estado africano poscolonial}

La segunda mitad del sigloXX y las primeras décadas del sigloXXI son fundamentales para comprender el lugar de África en el mundo contemporáneo y actual, así como para analizar la evolución de los sistemas políticos africanos en la era poscolonial, desde los regímenes de partido único instaurados tras la descolonización hasta la actual coyuntura de movilización masiva de la sociedad civil, pasando por la ola democratizadora de los años noventa y su involución posterior.

Al alba de las independencias se hizo evidente que la era colonial, a pesar de ser relativamente corta en el tiempo, había tenido un gran impacto en África. ${ }^{2}$ En

${ }^{2}$ En términos generales podemos considerar la colonización de África como un periodo que comienza 
efecto, el papel de las potencias imperiales europeas (Gran Bretaña, Francia, Alemania, Bélgica, Portugal, Italia y España) ha dejado un legado muy controvertido y duradero, con consecuencias que llegan hasta nuestros días.

Si bien los países africanos obtuvieron su independencia formal a partir de la década de los años cincuenta, y de manera multitudinaria en la década de los años sesenta y setenta, la independencia formal no constituyó en todo caso una independencia efectiva, ni política ni económicamente.

El proceso de transición desde la organización social colonial hasta la conformación de las naciones africanas independientes es un proceso complejo que debe analizarse con una perspectiva a largo plazo, ya que no se trata únicamente de observar la transferencia de la gestión de la administración a las nuevas autoridades, sino de comprender también la evolución de las estructuras políticas africanas en el periodo poscolonial, es decir, las diferentes fases que han atravesado los distintos países en el largo proceso que supone una descolonización real y estructural, elucidando las principales dinámicas políticas, económicas y sociales de las últimas décadas.

Por otra parte, la dominación colonial que establecieron las potencias imperialistas de Europa, y el proceso subsiguiente de descolonización e independencia africana constituyen uno de los gérmenes impulsores de la creación e institucionalización del sistema de la cooperación al desarrollo a nivel internacional a partir de la década de los años cincuenta. En efecto, el surgimiento de los nuevos países independientes africanos fruto del proceso de descolonización, con sus incipientes necesidades de asistencia técnica y financiera, junto con los cambios a nivel internacional derivados del final de la Segunda Guerra Mundial y del comienzo de la Guerra Fría, coadyuvaron al nacimiento de la cooperación al desarrollo (Alaminos Hervás, 2015).

con la celebración de la Conferencia de Berlín (1884-1885), donde se realiza el reparto del continente entre las principales potencias imperiales europeas, y termina en la década de 1960 (aunque como mencionamos anteriormente, algunos territorios accedieron a la independencia en las décadas posteriores de los años setenta, ochenta y noventa), es decir, un periodo histórico de aproximadamente setenta y cinco años. Los únicos países que no se incorporaron a los imperios coloniales fueron Etiopía y Liberia. En cierto modo, Liberia había sido "colonizada" por Estados Unidos, cuando los esclavos americanos liberados iniciaron el movimiento de retorno a África, fundando el Estado de Liberia en 1822 , declarado independiente en 1847. Los afroamericanos liberianos siguieron contando con el apoyo de Estados Unidos, que proporcionaron su asistencia para contener cualquier revuelta o enfrentamiento de la población nativa africana (Rosenberg, 1985; Seger, 2018). En el caso de Etiopía, algunos historiadores consideran que la estructura política, la unidad y control sobre el territorio, y la fortaleza de las instituciones fueron decisivos para que mantuviera su independencia ('t Hart, 2016; Tibebu, 1996). 
Además, con el advenimiento de la Guerra Fría, la confrontación bipolar Este-Oeste conllevó la rivalidad entre los dos bloques liderados por Estados Unidos y la Unión Soviética en un eje también Norte-Sur, mediante la lucha por zonas de influencia geoestratégicas en el denominado Tercer Mundo. Ello determinó la asignación y dirección de los flujos de la ayuda, que se vería condicionada por estos motivos geopolíticos (Alaminos Hervás, 2015; Griffin, 1991).

\section{I. El legado del colonialismo, descolonización y el auge del nacionalismo}

El análisis del legado colonial es un punto de partida ineludible para el estudio de África en la era poscolonial. A pesar de constituir un periodo relativamente corto y tardío, el dominio colonial es central para comprender el devenir del continente africano, dada su influencia e impacto en el desarrollo político y económico de África (Young, 1995). Sin ánimo de ser deterministas, y teniendo en cuenta que la herencia colonial no constituye en ningún caso el único factor para analizar el África contemporánea, abordaremos de manera resumida a continuación los principales elementos del legado colonial.

Es ampliamente conocido que los europeos dividieron África según sus intereses, repartiéndose los territorios sin tener en cuenta las afiliaciones étnicas o culturales de las sociedades africanas, ni las estructuras políticas preexistentes. ${ }^{3}$ La fragmentación del continente africano conllevó la imposición de fronteras y la conformación de Estados-nación modernos, conceptos exógenos al continente y al desarrollo de las unidades políticas precoloniales, generando de esta manera múltiples territorios con poca unidad interna, así como la división de grupos étnicos y culturales en diversos territorios separados por la demarcación de líneas fronterizas (Griffiths, 1995; Touval, 1972; Young, 1986; 1994; 1995). Aunque en África precolonial sí existían, en determinados territorios, entidades políticas de naturaleza superior, como Estados o Imperios, sus fronteras no eran fijas, se expandían y contraían continuamente, en función de las necesidades y del poder ejercido, y la autoridad política no se proyectaba a todos los confines del Imperio, sino que había una gran fluidez en el ejercicio de la soberanía y el movimiento de poblaciones (Mbembe,

\footnotetext{
${ }^{3}$ A pesar de que la mayoría de los Estados africanos son el resultado de la colonización por parte de las potencias europeas, algunos Estados africanos mantienen de manera significativa una cierta identidad precolonial. Young (1995) identifica los siguientes: Marruecos, Túnez, Egipto, Etiopía, Burundi, Ruanda, Madagascar, Suazilandia (Esuatini), Lesoto y Botsuana.
} 
2000). ${ }^{4}$ Con la incorporación formal de África al sistema internacional de Estados tras la colonización, las relaciones políticas y económicas del continente experimentaron cambios muy significativos. ${ }^{5}$

Algunas de las consecuencias de esta división realizada siguiendo una lógica externa al continente, en función de los intereses imperiales, y la consiguiente fragmentación en múltiples Estados modernos son muy relevantes en el ámbito económico y político, como veremos a continuación y a lo largo del artículo. ${ }^{6}$

Muchos autores consideran que las fronteras impuestas en el momento del reparto del continente han generado problemas sociales y políticos, al obviar la existencia y la naturaleza de las estructuras precoloniales africanas. La división de los territorios mediante fronteras artificiales ha generado la división de los pueblos y grupos étnicos africanos, dificultando la unión y cohesión de las entidades políticas independientes, y separando grupos culturales entre Estados diferentes. Ello habría coadyuvado, por un lado, a la existencia de disputas y conflictos internos, guerras civiles y movimientos secesionistas (como en el caso de Katanga, Biafra y Sudán del Sur); $y$, por otro lado, a fenómenos de irredentismo, como en el caso de Somalia (Griffiths, 1995; Herbst, 1992; 2000; Young, 1994; 1995).

${ }^{4} \mathrm{Mbembe}(2000$, p. 265$)$ considera que las actuales fronteras africanas no son únicamente el producto de la arbitrariedad colonial, sino que se deben analizar en el largo plazo para no simplificar las múltiples lógicas y génesis de tales fronteras: "Far from being simple products of colonialism, current boundaries thus reflect commercial, religious, and military realities, the rivalries, power relationships, and alliances that prevailed among the various imperial powers and between them and Africans through the centuries preceding colonization proper. From this point of view, their constitution depends on a relatively long-term social and cultural process".

${ }^{5}$ Para adquirir una visión general y comprehensiva del periodo precolonial, véanse, entre otros: Asante (2007), Coquery-Vidrovitch (2005), Davidson (1998), Ehret (2002) y Phillipson (1993).

"En la literatura africanista se suele hacer referencia al concepto de "balcanización" de África a la hora de analizar los efectos de este proceso de partición en el continente. Este término, aunque utilizado con connotaciones diferentes por diversos autores y dirigentes, proviene del entorno del nacionalismo africano, y fue utilizado por los principales líderes de la lucha anticolonial, como Kwame Nkrumah, Léopold Sédar Senghor o Sékou Touré, etc. Véase (Neuberger, 1976). Estos líderes lo utilizaron como analogía para comparar la situación de África en los albores de las independencias con el proceso europeo de disolución del Imperio austro-húngaro y la descomposición del Imperio otomano que generó el nacimiento de nuevos Estados independientes, los pequeños Estados balcánicos (o bien, la "balcanización" de esta región) en los siglos XIX y XX (Gellner, 1983; Hobsbawm, 1990; Hoffmann, 2008). 


\section{I.I. Nacionalismo africano}

Es importante tener en cuenta que los partidarios del panafricanismo, desde intelectuales africanos en la diáspora a partir de 1900, hasta los líderes de las independencias y del nacionalismo africano de los años cincuenta (siendo Kwame Nkrumah el mayor exponente de la unidad africana), debatieron en diversas conferencias panafricanistas ${ }^{7}$ sobre la problemática de las fronteras heredadas para los pueblos africanos, criticando su artificialidad y consecuencias para la división de los pueblos africanos, barajando la posibilidad de redibujar el mapa africano (Young, 1995).

Sin embargo, en la primera reunión de representantes de los Estados africanos independientes ${ }^{8}$, celebrada en Accra del 15 al 22 de abril de 1958, se llegó al acuerdo de aceptar las fronteras heredadas y respetar la integridad territorial de los Estados africanos. Nkrumah, el principal promotor de la unidad africana explicó tal consenso en aras de conseguir la paz y la estabilidad en los países emancipados:

Our conference came to the conclusion that in the interests of that Peace which is so essential, we should respect the independence, sovereignty and territorial integrity of one another (Nkrumah 1963, citado en Young, 1995, p. 23).

La Organización de la Unidad Africana (OUA), creada en 1963, expresó formalmente el principio de integridad territorial. En la Carta ${ }^{9}$ de dicha organización, surgida para erradicar el colonialismo, consolidar el proceso de descolonización y salvaguardar las independencias, se manifiesta el deseo de unidad africana y

${ }^{7}$ En la primera Conferencia de todos los pueblos africanos [All-African People's Conference], de carácter no gubernamental, celebrada en Accra (Ghana) del 8 al 13 de diciembre de 1958, se reunieron representantes de 28 países africanos, dependientes e independientes, incluyendo más de 300 líderes políticos y sindicales que representaban aproximadamente a 200 millones de africanos, además de países externos observadores. Los objetivos de la Conferencia, establecidos por el comité organizador compuesto por representantes de ocho Estados africanos independientes (Etiopía, Ghana, Guinea, Liberia, Libia, Marruecos, Túnez y la República Árabe Unida), se centraban en el apoyo a la acción de los movimientos nacionalistas para lograr las independencias, la unidad de los Estados libres, y la reconstrucción social y económica del continente (All-African People's Conferences, 1962). La siguiente conferencia de los pueblos africanos a nivel continental se celebró en Túnez, en 1960.

${ }^{8}$ En la Conferencia se condenó el colonialismo y la injerencia extranjera en los Estados emancipados, y se creó una Oficina Permanente para convocar, cada dos años, una nueva Conferencia interafricana. Las sucesivas Conferencias de Estados africanos independientes, de carácter gubernamental, se celebraron en Addis Abeba (1960) y El Cairo (1962).

${ }^{9}$ La Carta de la OUA se firmó el 25 de mayo de 1963 en Addis Abeba, por parte de los líderes de treinta y dos Estados africanos, día que ha pasado a considerarse el Día de África. 
solidaridad entre los Estados africanos. Sin embargo, incurriendo en cierta contradicción, por consolidar el sistema estatal, se enuncia solemnemente, en el párrafo 3 del artículo III, el principio de integridad territorial, y, por tanto, el corolario de la inviolabilidad de las fronteras, condiciones esenciales para garantizar la soberanía y la independencia de los nuevos Estados africanos. También en el preámbulo de la Carta se enuncia la resolución de consolidar la independencia, la soberanía y la integridad nacional de los países, exponiéndolo nuevamente en el artículo II, relativo a los objetivos de la Organización (OUA, 1963).

En la Conferencia cumbre de jefes de Estado y de Gobierno de la OUA, celebrada en El Cairo en 1964, se declaró formalmente el respeto de las fronteras existentes en el momento de accesión a la independencia, adoptando una resolución formal respecto a los litigios fronterizos entre Estados africanos (OUA, 1964).

De esta manera, las ambiciones más radicales del panafricanismo en el ámbito de la unión política, reflejadas en la obra seminal de Nkrumah, "Africa debe unirse" (Nkrumah, 1963), publicada en 1963 con motivo de la creación de la OUA, se diluyeron y se aceptó respetar la integridad territorial y las fronteras de los antiguos territorios coloniales, transformándolos en Estados independientes. Los padres del nacionalismo africano justificaron esta decisión en pos de la unidad nacional y la consecución de la estabilidad, para así poder comenzar a llevar a cabo políticas de desarrollo económico y consolidar los gobiernos poscoloniales.

Al mismo tiempo, las ideas panafricanistas no desaparecieron, y de hecho, contribuyeron, desde las independencias, al establecimiento de organizaciones regionales en el continente, en parte influenciadas por el legado de los agrupamientos de territorios coloniales (Bach, 2016). A pesar del protagonismo de las iniciativas de integración económica, en particular a partir de la década de los años ochenta, no debemos obviar los impulsos políticos de los procesos de integración, en marcha desde la constitución de la Unión Africana, heredera de la OUA, en el año 2000, con la ambición de superar el marco nacional y generar mecanismos de coordinación política y una mayor influencia internacional.

Los líderes nacionalistas fueron capaces de movilizar de manera muy amplia a las poblaciones de los Estados colonizados, aludiendo a la necesidad de ser autónomos política y económicamente, y liberarse del yugo colonial. El nacionalismo constituyó la principal fuerza motivadora y movilizadora para luchar por la liberación nacional y conseguir la independencia. No obstante, las diferencias internas en los Estados independientes suponían un obstáculo a la hora de desarrollar el proyecto de unión nacional. Si bien el Estado moderno había sido implantado 
en África, la construcción nacional no había tenido lugar. Los colonizadores en ningún caso habían fomentado la unión en sus colonias, ni habían penetrado el territorio hasta sus confines. El desafío para los primeros dirigentes poscoloniales, los padres fundadores, se centraba por tanto en conseguir vencer las diferencias internas, generar una unión nacional por encima de divergencias identitarias y étnicas y consolidar el rumbo del nuevo Estado fomentando políticas de desarrollo económico. ${ }^{10}$

\subsection{El camino hacia el autoritarismo poscolonial}

Los partidos políticos nacionalistas van a asumir el poder con la convicción de dar respuesta a los retos urgentes de unión interna, construcción de la administración, y, de manera muy relevante, la planificación de políticas económicas para conseguir el desarrollo, con la necesidad inmediata de obtener inversión y ayuda extranjera, que va a provenir no sólo de las antiguas potencias coloniales sino también de las dos superpotencias del momento, dado el contexto geopolítico de la Guerra Fría.

Tras el advenimiento de las independencias, los líderes nacionalistas y héroes de las luchas anticoloniales, tendieron al establecimiento de regímenes de partido único, con el pretexto de no dar lugar a la división interna, consolidar el Estado y unir los elementos de la sociedad. Si bien en el momento de la descolonización, las justificaciones parecían pertinentes, dadas las características del nacimiento de los Estados africanos, y la necesidad de unión y desarrollo económico, vamos a asistir progresivamente, en las primeras décadas de los Estados emancipados, al creciente control del Estado por parte de una élite política, representada en un único partido, que concentra el poder y los recursos.

La urgencia de establecer un gobierno efectivo y sentar las bases para el desarrollo económico justificó, por tanto, la disminución del pluralismo y la eliminación de grupos profesionales y de oposición política. Aunque, evidentemente, cada Estado

\footnotetext{
10 Una visión general de los debates en torno a la relación entre etnia y el nacionalismo africano, que exceden el alcance de este artículo, puede leerse en Young (1994b) y Yeros (1999). Sobre la tensión entre nacionalismo y secesionismo, consúltese por ejemplo Engleberty Hummel (2005) y Spears (2004). En este último aspecto, a pesar de la existencia de tensiones internas, las fronteras coloniales se han mantenido sorprendentemente estables, y no hemos asistido en ningún caso a una proliferación de modificaciones territoriales, exceptuando algunas excepciones, como la unión de Tanganica y Zanzíbar para constituir Tanzania (1964), la independencia de Eritrea de Etiopía (1993), o la secesión de Sudán del Sur de Sudán (2011).
} 
africano es diferente, y los gobiernos poscoloniales de partido único no son similares ni actúan de la misma manera, la acumulación de los recursos, la corrupción y la falta de participación de la sociedad civil van a ser elementos comunes en la primera generación de gobiernos poscoloniales.

Este proceso está relacionado con la naturaleza de la construcción de los Estados-nación africanos y las características de las instituciones políticas legadas por el colonialismo. Para Badie (1992), la corrupción y el autoritarismo de los gobiernos africanos poscoloniales serían la consecuencia de la exportación del modelo de Estado europeo y el intento de occidentalización del orden político sin tener en cuenta las tradiciones propias de organización social y política. Por otro lado, Bayart (1989) considera que se trata de un fenómeno híbrido, ya que a la importación del Estado europeo se superpone la reapropiación africana de las instituciones heredadas de los colonizadores. El acceso al Estado va a suponer la fuente de enriquecimiento y de ascensión social, generándose una élite política dominante que controla el Estado y los recursos. Asimismo, los gobiernos africanos utilizarán distintas estrategias para obtener recursos del exterior con el propósito de utilizarlos internamente para su beneficio, según el concepto de 'extraversión' enunciado por Bayart.

La relación entre colonizadores y colonizados es una interacción eminentemente asimétrica, pero la población africana va a generar mecanismos de adaptación y resistencia para contrarrestar la explotación de las burocracias coloniales. Diversas movilizaciones africanas van a tener lugar desde el principio del colonialismo, y en los últimos años una pequeña parte de la población, perteneciente al entorno urbano, una pequeña élite educada y asalariada, que había colaborado con las administraciones coloniales, va a desafiar a los gobiernos coloniales, iniciando el camino hacia las independencias (Cooper, 2002; 2005).

En este sentido, uno de los legados más relevantes del colonialismo en la esfera política es el autoritarismo de la administración colonial, que va a manejar el principio de "divide y vencerás" para evitar desafíos y resistencias a la autoridad colonial. El poder colonial se encontraba concentrado en una pequeña administración europea, cuyo objetivo era generar una estructura política suficiente para explotar los recursos humanos y materiales de manera efectiva y poco costosa. El gobierno colonial se centraba en las zonas urbanas y las regiones con recursos, marginando política y económicamente a las regiones periféricas del Estado, mayoritariamente rurales, generando una dicotomía centro-periferia y asimetrías estructurales dentro de los Estados (Mamdani, 1996). 
Algunos autores consideran que los problemas de los Estados africanos poscoloniales provienen de la debilidad estructural de las instituciones y la capacidad estatal. La creación de los Estados africanos es totalmente diferente de la creación de los Estados europeos, dados los factores explicitados anteriormente. En el periodo colonial, las potencias imperiales, como hemos visto, no tenían la voluntad de establecer un Estado fuerte, sino una mínima administración para gestionar sus intereses, prioritariamente la explotación de los recursos naturales y mano de obra africana. Una vez obtenida la independencia, los gobiernos africanos heredaron estos Estados carentes de fortaleza institucional, así como unas fronteras que dificultaban la unidad nacional. En consecuencia, muchos gobiernos africanos fueron incapaces de proyectar su autoridad en todo el territorio definido por las fronteras, y tampoco consiguieron la lealtad de los ciudadanos de todas las regiones. Los líderes, progresivamente, viraron hacia el autoritarismo, y los Estados siguieron, como en el periodo colonial, marginando las zonas rurales. Se priorizaron las zonas urbanas respecto a las regiones periféricas, donde vive la mayor parte de la población, favoreciendo la distribución de los recursos entre las poblaciones urbanas, sumiendo en la pobreza a las zonas más alejadas de la administración central (Herbst, 2000).

El afropesimismo característico de los años ochenta proviene, en parte, de la constatación del asentamiento duradero en el continente africano de regímenes autoritarios. En general, estos regímenes se van a instaurar en el momento de las independencias y de la construcción de las incipientes naciones africanas poscoloniales, y van a ostentar el poder hasta la década de los años noventa, cuando el continente experimenta una ola democratizadora que cambia los sistemas políticos de manera progresiva en casi todos los países.

\subsection{Supervivencia del estado y neopatrimonialismo}

El mantenimiento de los Estados africanos hasta el día de hoy es un fenómeno de interés particular, si tenemos en cuenta el punto de partida de los mismos. En efecto, los Estados africanos independientes, como vimos anteriormente, fueron creados por el colonialismo, al igual que el trazado de sus fronteras, sin tener en cuenta las estructuras e identidades precoloniales, y enfrentaron rápidamente problemas de desarrollo económico que dificultaron su viabilidad en un sistema internacional dominado por Estados con más poder e influencia.

Según las tesis de Clapham (1996) una de las claves fundamentales para comprender la permanencia de los Estados africanos en el tiempo es la acción de 
los dirigentes políticos africanos para conseguir la supervivencia de los Estados, y por ende, su supervivencia como líderes. En muchos casos, los gobernantes poscoloniales se centraron en garantizar su bienestar y seguridad, utilizando el control de las instituciones políticas para su beneficio. Esto ha conllevado el establecimiento de "shadow states", Estados que ostentan una apariencia formal estatal, pero esconden estrategias de supervivencia personal. Así pues, la fachada estatal proporcionaría la legitimidad necesaria a estos dirigentes para mantenerse en el poder, y los objetivos declarados por los Estados de desarrollo económico y unidad nacional quedarían en un segundo plano, priorizando los objetivos de los gobiernos personalistas, como el enriquecimiento propio.

Las deficiencias y debilidad en la institucionalización de los Estados africanos generarían, entonces, un alto grado de "desorden" que va a ser aprovechado por las élites africanas para instaurar un sistema de patrimonialismo y clientelismo orientado a su beneficio y supervivencia. Los sistemas políticos heredados en las independencias han sido reconfigurados (y "africanizados") por las circunstancias del periodo poscolonial y por la cultura política de los Estados africanos independientes. La característica principal del patrimonialismo y desorden poscolonial sería su carácter informal y personalista, generando la confusión de lo público y lo privado, y una relación entre las élites políticas y la sociedad basada en prácticas de clientelismo, redistribuyendo recursos para garantizar la legitimidad del gobierno (Chabal y Daloz, 1999).

Ahondando en el análisis del Estado africano, Médard (1991) va a introducir, a partir de las categorías weberianas de dominación, el concepto de "neopatrimonialismo" para caracterizar al Estado africano y abordar la problemática de la corrupción en la vida política de los Estados africanos. El prefijo "neo" pretende marcar la diferencia respecto de los regímenes patrimoniales tradicionales y especificar la particularidad del continente africano en cuanto a la confusión de la esfera pública y privada fuera del ámbito tradicional, al existir precisamente la estructura de un Estado moderno. El neopatrimonialismo supone, por tanto, una situación mixta o híbrida, según la cual encontramos, por un lado, la estructura formal de un Estado burocrático, y por otro lado, una élite política que personaliza el poder, acumula los recursos y actúa mediante el clientelismo y el patronazgo, u otras formas de dominación patrimonial. La fachada del Estado ocultaría entonces un gobierno personalista que va a consolidar su hegemonía dentro de este orden neopatrimonial, monopolizando el poder y estableciendo redes clientelares con grupos de interés. Para Médard (1992), los "Big man" africanos son "políticos empresarios", no hay diferencia clara entre los ámbitos de acción. Su actuación evidencia la importancia de las lógicas, verticales, 
informales y personalistas, y la instrumentalización de lo público en aras de satisfacer los intereses individuales.

Las tesis del (neo)patrimonialismo en los debates sobre el Estado en África explican el funcionamiento de los gobiernos africanos desde una perspectiva comprehensiva, que liga su desempeño a la herencia colonial y a la acumulación de los recursos por parte de las élites gobernantes poscoloniales. Suponen también un intento de superar determinados análisis políticos clásicos, ampliando el espectro a otros niveles y características del ejercicio del poder fuera de las instituciones. Las características de los gobiernos personalistas ${ }^{11}$ y la informalización de la política resultan fundamentales para comprender la instrumentalización del Estado y las relaciones de clientelismo entre las élites y sus bases de apoyo, desarrolladas en muchas ocasiones siguiendo lógicas de afiliación étnica, cultural o religiosa. Como afirma Clapham (1996, p. 13), la legitimidad basada en principios no democráticos será sólo respetada por aquellos que se beneficien de ella. Desaparece entonces la relación moral y el contrato social entre gobernantes y gobernados, y los dirigentes actuarán meramente en su nombre y el de sus partidarios. En estas circunstancias, hablar de "Estado" puede ser equiparable a hablar de la élite dominante que ostenta el poder.

Las redes clientelares internas coexisten, además, con un patronazgo externo, ya que los dirigentes políticos africanos se van a apoyar en actores externos para conseguir la supervivencia de los Estados y su mantenimiento en el poder. Sin embargo, los cambios operados en el orden mundial van a generar fluctuaciones que afecten profundamente el devenir de los Estados africanos, como veremos a continuación.

Si bien durante las décadas de los años sesenta y setenta, el apoyo de Estados Unidos y la Unión Soviética a los países afines ideológicamente en sus respectivas esferas de influencia va a ser determinante para la supervivencia de los Estados, esta situación va a cambiar a lo largo de los años ochenta y con el desmoronamiento de la Unión Soviética a partir de 1989, se reducirán abruptamente los flujos de ayuda a los países africanos, lo cual tendrá un efecto directo en la caída de los primeros gobiernos africanos de la era poscolonial.

"En función de sus características, Jackson y Rosberg (1982) dividen los tipos de gobiernos personalista en África en cuatro tipos: el príncipe, al autócrata, el profeta y el tirano. 


\subsection{Idas y venidas de la democratización}

El descontento de las sociedades africanas con los gobiernos personalistas va a culminar con una serie de protestas y revueltas en la década de los años noventa, que va a conllevar la democratización de casi todos los países del continente. ${ }^{12}$ La denominada "tercera ola democratizadora" de los años noventa, o "segunda liberación", va a arrasar el continente africano, generando gran euforia y esperanzas de cambio estructural hacia la democracia en África.

La creación y la naturaleza de los Estados africanos son fundamentales para comprender sus relaciones con la sociedad. Asimismo, las desigualdades en el ámbito del acceso a los recursos políticos y económicos van a tener una relación directa con el auge de las protestas y las rebeliones en contra de los regímenes políticos poscoloniales.

En general, los gobiernos africanos han tenido mucho cuidado con contentar a las poblaciones urbanas, mediante subsidios y otros mecanismos, mientras que se ha sometido a la recaudación de tributos a las regiones periféricas, más pobres, con el objetivo de evitar protestas contra la autoridad gubernamental en las zonas centrales de los países (Bates, 1981).

No obstante, en los años noventa se dio una conjunción de circunstancias internas y externas que favoreció la transición del autoritarismo al pluralismo. Por un lado, la falta de legitimidad del Estado poscolonial y la acumulación de recursos, que había favorecido a una pequeña parte de la población en detrimento de la mayoría, va a generar la movilización de la sociedad civil en contra de tales abusos, manifestándose por la instauración de un nuevo orden político. Por otro lado, el contexto internacional del final de la Guerra Fría, el desmoronamiento de la URSS y la caída de los regímenes del Este de Europa. Por último, el apoyo de la Comunidad internacional a las iniciativas de democratización, con la imposición de condiciones políticas a la provisión de ayuda, van a coadyuvar al éxito del proceso.

El proceso de cambio político y democratización va a estar, por tanto, guiado por la movilización de las citadas fuerzas internas, e influenciado por el contexto

\footnotetext{
${ }^{12} \mathrm{El}$ continente africano va a evolucionar, en la década 1989-1999, desde regímenes de partido único o regímenes militares, hacia el multipartidismo. El continente va a pasar de 29 sistemas de partido único, a 1 , y de 9 a 45 sistemas políticos multipartidistas, que van a promover la celebración de 192 elecciones presidenciales y legislativas. Véase Carbone (2007) y Jacquemot (2020).
} 
geopolítico del final de la Guerra Fría, que va a suponer el fin de la asistencia, por parte de Estados Unidos y la Unión Soviética, a regímenes afines ideológicamente.

Los países africanos obtuvieron su independencia en plena primera fase de la Guerra Fría, y, por ende, se vieron impelidos a posicionarse en un sistema internacional dominado por las dos superpotencias. Aunque muchos países africanos apoyaron las tesis del no alineamiento, el continente africano pronto se convirtió, como el resto de los continentes, en el campo de batalla (ideológico y también territorial) de los dos bloques. La Unión Soviética apoyó militar y financieramente a los nuevos Estados soberanos con ideologías afines y regímenes declarados socialistas tras las independencias. Los Estados Unidos, por su parte, llevaron al continente africano su política exterior de contención del comunismo, apoyando a Estados regionalmente relevantes frente al avance del socialismo en África (Crawford, 1985; Gavshon, 1981).

Por su parte, las relaciones de la Comunidad Europea con el mundo en vías de desarrollo se definieron en un primer momento en torno a un concepto (caracterizado por Holland como "miope") francófono del Tercer Mundo, centrado esencialmente en el fomento de un marco prioritario de relaciones con las dependencias coloniales francesas en África (Holland 2002, p. 25). Los primeros programas europeos de ayuda, aunque marcados por el conflicto Este-Oeste y por la influencia manifiesta de Estados Unidos, reflejan en mayor medida los intereses particulares regionales de las principales potencias coloniales europeas, las relaciones de Francia con el África francófona, y posteriormente de Reino Unido con los países de la Commonwealth (Griffin 1991, p. 647).

Durante la Guerra Fría, las dos superpotencias intervinieron directamente en la política de muchos Estados africanos, en función de sus propios intereses de política exterior, proveyendo asistencia económica y militar para sostener a los regímenes afines. La ayuda exterior, otorgada por la dependencia y la vinculación a uno de los dos bloques, ayudaron a la supervivencia de los Estados africanos, aunque la protección no fue evidentemente desinteresada, sino que exigía un intercambio de beneficios, fuera en términos de importancia de la localización estratégica, clientelismo diplomático y político, u oportunidades económicas (Clapham 1996, p.20).

Con el desmoronamiento de la Unión Soviética y el final de la Guerra Fría, la relevancia estratégica del continente africano decayó y las relaciones de patronazgo disminuyeron radicalmente o desaparecieron, dado el coste de mantener a los Estados. Esto provocó el fin del apoyo a los gobiernos clientes de las potencias de la Guerra Fría, coadyuvando a su caída. Otra de las principales consecuencias para 
el continente africano fue el fin de las guerras indirectas (o proxy wars) libradas en el continente, al desaparecer la financiación externa y el suministro de armamento. ${ }^{13}$

Otro cambio fundamental en el continente africano con el fin de la Guerra Fría va a ser el auge de la presencia china en el continente. Si bien los principales actores europeos van a seguir presentes e implicados en el continente, de manera particular Francia y Reino Unido, va a ser China quien muestre un mayor interés e inicie una creciente cooperación en el ámbito económico y comercial. Las relaciones diplomáticas y económicas de China con los países africanos no han cesado de crecer hasta el día de hoy, incluyendo también cooperación política, militar y humanitaria (Alden, 2007; 2018; Taylor, 2009).

Aunque el advenimiento del llamado Nuevo Orden Internacional no va a suponer el fin de la ayuda al desarrollo proveniente de Occidente, en los años noventa vamos a asistir a una transformación profunda de las relaciones Norte-Sur. Con el final de la Guerra Fría, los flujos de ayuda van a dejar de seguir una lógica geopolítica, y ante los límites de las reformas económicas realizadas bajo los auspicios de las Instituciones Financieras Internacionales, se van a adoptar nuevos enfoques caracterizados por el énfasis en el respeto de los derechos humanos, la democracia y el buen gobierno (los denominados criterios de condicionalidad política), que van a suponer una presión suplementaria para la democratización de los países africanos. Como dice Young (2012): "the sudden evaporation of external indulgence of autocratic rule sent shock waves throughout Africa".

En este sentido, las políticas de promoción de la democracia y las cláusulas de condicionalidad política van a ser duramente criticadas por los gobiernos africanos como nuevas formas de injerencia externa en la soberanía del Estado, y los líderes van a intentar reafirmarse en su posición de poder, aunque sea a costa de coartar las libertades de la sociedad civil, y de impedir el ejercicio de la oposición política.

De esta manera, el afrooptimismo de principios de los años noventa va a desaparecer gradualmente y va a dar lugar de nuevo al afropesimismo a medida que se observen los resultados efectivos del proceso de democratización en el continente. La evolución de los acontecimientos muestra, a partir del nuevo milenio, un retro-

\footnotetext{
${ }^{13}$ En el inicio de la pos Guerra Fría, asistimos en el continente a la proliferación de procesos de negociación y resolución de conflictos, conflictos que habían sido alimentados por el flujo de recursos del exterior durante el periodo de la Guerra Fría. Es el caso, con desiguales resultados, en Etiopía, Angola, Congo o Sudáfrica. Véase Westad (2005) para el análisis de las intervenciones en el Tercer Mundo durante la Guerra Fría; y Keller y Rothchild (1996) para el periodo de la pos Guerra Fría y el Nuevo Orden Internacional.
} 
ceso en la transición a la democracia, con la proliferación de golpes de Estado y la ambición de los líderes políticos de mantenerse en el poder más allá del límite establecido constitucionalmente para gobernar (Clapham, 1993; Ihonvbere, 1996; Wiseman, 1996).

La sociedad civil africana va a mostrar su hartazgo nuevamente a partir del nuevo milenio, incluso en espacios políiticos muy cerrados con líderes propensos a ejercer la represión violenta contra su población. De esta manera, a partir de 2005 y sobre todo de 2010, asistimos a una movilización multitudinaria de las sociedades africanas de muchos países, que salen masivamente a la calle para protestar contra las élites acumuladoras y corruptas, en busca del cambio político y la justicia social. Los desencadenantes de la que ya se denomina "cuarta ola democratizadora" son variados (subida de los precios, eliminación de subsidios, crisis económica...) pero en muchos escenarios van a derivar rápidamente en reclamaciones de cambio político y de índole social (Alaminos Hervás, 2019).

Las movilizaciones y revueltas en el continente africano tienen una larga trayectoria histórica, desde las luchas por la liberación nacional, contra el colonialismo, hasta la oposición en contra de los regímenes poscoloniales de partido único y las medidas de austeridad económica. Los movimientos contemporáneos y actuales ${ }^{14}$ no son movimientos de ruptura radical, sino la continuación de esas dinámicas históricas de movilización en contra del funcionamiento de los gobiernos, tanto coloniales, como poscoloniales, en el ámbito político y económico. Asimismo, resultan precedentes fundamentales para comprender la actual ola de protestas a nivel global.

Es pronto para poder observar los resultados efectivos de este proceso, hay avances en algunos países, pero también hay escenarios en los que la respuesta gubernamental ha promovido una mayor represión y vigilancia de los ciudadanos, con el objetivo de evitar los levantamientos y protestas (Cheeseman, 2015).

Para concluir esta sección del artículo, centrada en los vaivenes y fluctuaciones en el desarrollo político de África en el periodo poscolonial, recordemos que la gobernanza de los Estados africanos poscoloniales es evidentemente compleja, y remite a la consideración de factores tanto internos como externos. Por un lado, el papel de los héroes de las independencias y padres fundadores es controvertido, ya que su legitimidad por haber liderado las luchas por la liberación nacional se ve empañado por el establecimiento de gobiernos poscoloniales de carácter

${ }^{14}$ Por ejemplo: Occupy Nigeria, las revueltas sudanesas, las protestas en Uganda, Etiopía, Burundi, Burkina Faso, Sudáfrica, Senegal, etc. 
autoritario, con sistemas de partido único que marginaron la participación de gran parte de la sociedad civil en la vida política y económica de los países, a pesar de la justificación de la situación excepcional de estos países, y la urgencia del establecimiento de una administración poscolonial para iniciar la formulación de políticas de los países. La segunda generación de dirigentes poscoloniales va a intentar, en muchos casos, reforzar su posición en el poder, garantizándose así el acceso a los recursos económicos de los Estados, y traicionando el objetivo de desarrollo político y económico de los países en aras de su beneficio personal.

\section{Economía política del desarrollo africano}

Los malos resultados en materia de desarrollo económico en África contrastan con la riqueza del continente en cuanto a recursos naturales. A pesar de la abundancia de recursos, África es el continente con el mayor número de países menos desarrollados y los peores indicadores macroeconómicos. Las últimas seis décadas son fundamentales para analizar la evolución de las economías africanas y la inserción de África en la economía internacional, con sus desigualdades y asimetrías.

Como es conocido, la soberanía de un Estado-nación viene determinada, entre otros criterios, por la autonomía que dicho Estado ostenta respecto a la capacidad plena de tomar decisiones, entre otros, en el ámbito de la política económica. El caso de África es particular en este sentido, ya que, aunque la mayoría de los países africanos obtuvieron su independencia formal hace ahora sesenta años, no podemos afirmar que dicha independencia se haya concretado económicamente.

Tras las independencias, la influencia de las antiguas potencias coloniales se ha percibido como la continuación de la injerencia y la dominación por otros medios, políticos y económicos. Su colaboración o intervención directa en los Estados africanos ha proseguido, en mayor o menor medida, hasta el día de hoy, y su presencia, junto con la aparición de otros actores interesados en los recursos y estabilidad del continente (de forma particular China, pero también Estados Unidos y Rusia), representa un desafío para la soberanía efectiva de los países africanos.

El pasado colonial e imperial europeo ha influido enormemente también en la forma que adoptaron las relaciones iniciales entre la Comunidad Europea y Áfri$\mathrm{ca}$, relaciones euro-africanas que son "as old as the European Community itself" (Holland 2002, 1), así como en las implicaciones políticas y económicas que ello ha conllevado hasta el día de hoy. 


\section{I. El legado del colonialismo y la crisis de la deuda}

La cuestión de la inserción de África en la globalización es fundamental en el análisis de la economía política africana, debido a la influencia de los actores externos y a las singularidades del continente africano. El análisis de la inserción de África en la economía internacional debe comenzar necesariamente antes de la consecución de la independencia por los Estados africanos, ya que, en el periodo colonial, África no se encontraba aislada, sino al contrario, el modelo extractivo colonial fomentó lógicas económicas internacionales, en particular en lo que respecta al flujo de los recursos desde los países africanos hacia las metrópolis.

El legado del colonialismo es, de nuevo, un punto de partida imprescindible. Por una parte, las fronteras arbitrarias no tuvieron en cuenta las necesidades e imperativos económicos de los africanos. Se constituyó una multiplicidad de pequeños Estados, con poco territorio y recursos escasos, dificultando de esta manera la viabilidad económica una vez obtenida la independencia formal. ${ }^{15}$ Asimismo, las fronteras dibujadas por los europeos han generado más Estados sin salida al mar que en ningún otro continente, obstaculizando las posibilidades de comercio y el transporte de las importaciones y exportaciones, lo cual ha tenido consecuencias a largo plazo que se manifiestan en los problemas de subdesarrollo económico. ${ }^{1617}$

\footnotetext{
${ }^{15}$ De acuerdo con el Departamento de la Asamblea General y de Gestión de Conferencias de Naciones Unidas (https://www.un.org/dgacm/es/content/regional-groups), África cuenta en la actualidad con cincuenta y cuatro Estados soberanos, que conforman el grupo regional africano de Estados miembros de Naciones Unidas.
}

${ }^{16}$ África cuenta en la actualidad con dieciséis Estados sin salida al mar: Botsuana, Burkina Faso, Burundi, Chad, Esuatini (antes Suazilandia), Etiopía, Lesoto, Malawi, Mali, Níger, República Centroafricana, Ruanda, Sudán del Sur, Uganda, Zambia, Zimbabue, de acuerdo con la lista informal aceptada por Naciones Unidas (https://unctad.org/topic/landlocked-developing-countries/list-of-LLDCs). Trece de estos Estados se encuentran también en la categoría de países menos desarrollados o adelantados del planeta (las excepciones son Bostuana, que se graduó en 1994 de la lista, Esuatini y Zimbabue), por cumplir los criterios de inclusión en la lista, a saber, la renta per cápita, el capital humano y la vulnerabilidad económica, y constituir "países de bajos ingresos que sufren los impedimentos estructurales más graves para el desarrollo sostenible", según la definición de Naciones Unidas (http://unohrlls. org/about-ldcs/ y https://unctad.org/topic/least-developed-countries).

${ }_{17}$ Para Collier (2008), África constituye el núcleo central para analizar las problemáticas de los países más pobres (o pertenecientes al "bottom billion", como él los denomina), ya que la mayoría de los países africanos están atrapados en una $u$ otra de las cuatro trampas para el desarrollo que identifica el autor: la trampa del conflicto, la trampa de los recursos naturales, ser un país sin litoral y con malos vecinos, y los problemas del mal gobierno en pequeños Estados. En términos generales, actualmente se estima que aproximadamente el treinta por ciento de la población africana vive en países sin litoral y con pocos recursos, rodeados además por otros países pobres (Dunne 2015). 
Además, el escaso desarrollo de las comunicaciones e infraestructuras remitía siempre al interés colonial, beneficiando el acceso a las localizaciones con recursos y a los puertos, para la exportación hacia las capitales de las metrópolis, generando relaciones de dependencia.

En el periodo colonial, se favoreció esencialmente el desarrollo del sector primario, mediante actividades económicas de recolección agrícola y extracción de los recursos minerales del continente, para su exportación hacia las metrópolis europeas. Los europeos no buscaron en ningún caso el desarrollo de productos manufacturados, sino que se centraron en la obtención de materias primas que beneficiaran a las potencias imperiales. Tampoco se planteó el desarrollo de infraestructuras, salvo una mínima red de comunicación para favorecer el transporte hasta las plantaciones y minas, o hacia los puertos, desde los cuales se enviaban los recursos a Europa. En consecuencia, esta especialización en la exportación de productos primarios no generó desarrollo local, dado que la extracción de los recursos y sus beneficios se dirigían únicamente hacia el Norte, por lo que diferentes autores y teorías, como las teorías de la dependencia, consideran que la acción europea en la explotación de los recursos africanos es la causa primigenia del subdesarrollo de África (Ake, 1976; 1981; Rodney, 1972).

El fin del colonialismo no trajo consigo, sin embargo, el final de la explotación de los recursos africanos, sino que las antiguas metrópolis mantuvieron su influencia en las economías africanas. De hecho, ya en los albores de las independencias surgió la preocupación a este respecto y los países africanos comenzaron a criticar el neocolonialismo o la continuación de las prácticas de dominación por otros medios. En palabras de Nkrumah (1965, p. ix):

The essence of neo-colonialism is that the State which is subject to it is, in theory, independent and has all the outward trappings of international sovereignty. In reality its economic system and thus its political policy is directed from outside.

Una vez obtenida la independencia, los Estados africanos tenían como misión prioritaria generar el desarrollo de sus países. Sin embargo, el punto de partida, dados los factores comentados anteriormente, suponía una posición de desventaja desde el punto de vista internacional. Los países africanos se habían especializado en el sector primario, y habitualmente, en la producción de sólo dos o tres productos agrícolas o minerales, orientados a la exportación. Se estima que más de treinta países africanos llegaron a depender de los productos primarios para más del setenta y cinco por ciento de sus ingresos de exportación; y dichos ingresos constituían para los países más de la cuarta parte de todos sus ingresos (Brown, 1995 , p. 22 y 28$).$ 
De esta manera, la falta de diversificación de las incipientes economías africanas mostraba una debilidad estructural, al ser productores de pocos productos primarios con poco valor añadido y compradores de productos manufacturados, mucho más costosos. Además, la dependencia de los mercados europeos, compradores tradicionales de sus productos, así como las fluctuaciones de los precios de dichos productos primarios, los situaban en una posición de vulnerabilidad.

En este contexto, uno de los primeros objetivos de la primera generación de gobiernos poscoloniales, va a ser intentar romper el círculo vicioso de la especialización en pocos productos del sector primario, generar infraestructura y planes de industrialización. Para comenzar estas transformaciones estructurales, los Estados africanos van a pedir ayuda financiera a las antiguas metrópolis, iniciando en la década de los años sesenta la implementación de políticas de desarrollo orientadas a terminar con la dependencia y generar crecimiento económico, lo cual van a conseguir, dada la alta demanda de materias primas por parte de los países del Norte. Se estima, desde mediados de los sesenta hasta el primer shock petrolero de 1973, un crecimiento de la inversión directa extranjera a una tasa anual del 6.4 por ciento, y un crecimiento medio anual del 4.5 por ciento, aunque los intercambios comerciales van a seguir estando orientados en su mayoría a las antiguas potencias coloniales (Colom Jaén, 2007, p. 10).

A pesar del optimismo inicial, la crisis global producida en la década de los años setenta, con la subida de los precios del petróleo en 1973, y de nuevo en 1979, va a tener un efecto directo en las economías africanas. Los precios de los productos básicos, fundamentales para las economías africanas, van a caer, mientras que las manufacturas van a encarecerse, empeorando las condiciones de intercambio para los países africanos. La reducción drástica en los ingresos va a traducirse en un endeudamiento externo, al no poder devolver los préstamos con los ingresos provenientes de las exportaciones, dado el descenso radical de los precios de los productos primarios, y la falta de diversificación de las economías africanas A pesar de que en 1980 los países africanos diseñaron un nuevo proyecto colectivo de desarrollo, bajo el Plan de Acción de Lagos, la petición de nuevos préstamos y el aumento de las tasas de interés a partir de la crisis de 1979 conllevaron consecuencias desastrosas para los países africanos, manifestadas en la crisis de la deuda de los años ochenta y noventa (Cheru, 1990; Colom Jaén, 2007). 


\subsection{La era del ajuste estructural}

Ante la espiral de la crisis de la deuda africana, se recurrió a mecanismos de financiación multilateral. La respuesta de las Instituciones Financieras Internacionales (IFIs) fue la formulación de Programas de Ajuste Estructural (PAEs) a partir de los años ochenta.

El denominado Informe Berg del Banco Mundial (1981), en su diagnóstico sobre los problemas económicos de África, la crisis y el endeudamiento durante las décadas de los años sesenta y setenta, otorgó una importancia preponderante a los "problemas estructurales internos" y formuló una estrategia de desarrollo para la década de los años ochenta basada en la agricultura y en las exportaciones, preconizando la apertura de las economías africanas para conseguir el crecimiento económico.

Los PAEs se empezaron a implementar a principios de los años ochenta, y a finales de la década de los noventa, la mayoría de los países africanos, incluyendo algunos de los más reacios a los programas, se habían adherido a ellos ante la imposibilidad de encontrar otras fuentes de financiación con las que llevar a cabo sus políticas económicas. El acceso a los préstamos de las IFIs no era evidentemente sin condiciones, sino que implicaba la aceptación de una serie de reformas en las políticas económicas de los países, en línea con lo estipulado en el Informe Berg: liberalización, apertura de las economías, énfasis en la producción agrícola y las exportaciones como preludio de la industrialización, que llegaría más tarde, y disminución del papel del Estado en la economía.

Estas directrices liberales recondujeron las políticas africanas en una dirección radicalmente diferente a la emprendida por la primera generación de gobiernos africanos poscoloniales, que habían promulgado un papel predominante para el Estado, e iniciativas que superaran la dependencia y la falta de diversificación de las economías tras el colonialismo, como vimos anteriormente.

Los resultados de crecimiento económico han sido bastante modestos, como se observa en un informe del propio Banco Mundial (1994): "On the macroeconomic front, six of the adjusting countries had a large improvement in policies, nine a small improvement, and eleven a deterioration", aunque afirman "most countries that improved their policies have returned to positive rates of GDP per capita growth". Otros informes, sin embargo, son más escépticos y muestran las limitaciones del enfoque del ajuste frente a una aproximación transformadora de las estructuras políticas y económicas que consiga la autosuficiencia y el desarrollo sostenible a largo plazo (UNECA, 1990). 
En términos generales, los Programas de Ajuste Estructural reprodujeron la situación de desventaja de los países africanos en términos de falta de diversificación de las economías y concentración en la exportación de productos primarios, lo cual ha resultado un obstáculo para una transformación estructural del continente, que incluyera la industrialización y generación de infraestructuras, para una inserción en la economía internacional desde una posición menos dependiente y asimétrica.

Además, los PAEs también tuvieron consecuencias sociales y políticas muy importantes, al disminuir el rol del Estado, los subsidios a productos de primera necesidad y el gasto en servicios públicos, afectando a las necesidades de las capas más vulnerables de la población, que no van a tener acceso a los servicios básicos, y provocando la extensión de la pobreza y el aumento de las desigualdades sociales (Cheru, 1999; Colom Jaén, 2007).

Los efectos y consecuencias del ajuste estructural en el continente africano han generado eternas discusiones entre los políticos y ríos de tinta entre los académicos. Sin entrar en detalles, dada la profusa literatura al respecto, a día de hoy resulta evidente que el ajuste estructural no ha traído al continente un alto grado de desarrollo ni de reducción de la pobreza. No obstante, no se puede responsabilizar únicamente a los PAEs de la coyuntura económica y social de África Subsahariana, ni desresponsabilizar a los gobiernos africanos previos al ajuste, bajo cuyos mandatos también se había extendido la pobreza y el crecimiento económico había resultado elusivo.

\subsection{Iniciativas africanas y alivio de la deuda}

En la 37 Cumbre de la OUA celebrada en Sirte (Libia) en 2001, se decidió inaugurar el Nuevo Partenariado para el Desarrollo Africano (NEPAD), ratificándolo en la primera cumbre de la UA, en 2002. Resultado de la fusión, bajo el impulso del entonces presidente de Sudáfrica, Thabo Mbeki, de dos iniciativas previas para el desarrollo africano ${ }^{18}$, la "Nueva Iniciativa Africana" tomó su nombre final "NEPAD" y se constituyó en uno de los programas fundamentales de la UA para la erradicación de la pobreza, la promoción del crecimiento económico y la integración de África en la economía internacional (Kanbur, 2002; UA, s.f.). Los resultados limitados del NEPAD, su adherencia al Consenso de Washington

${ }^{18}$ El Millennium Partnership for the African Recovery Programme, lanzada por los líderes de Sudáfrica (T. Mbeki), Argelia (A. Buteflika) y Nigeria (O. Obasanjo); y el OMEGA Plan for Africa impulsada por el presidente de Senegal (A. Wade). 
y la falta de participación de la sociedad civil en el proceso de su creación, han generado críticas sobre el NEPAD y su potencial para el continente (Kajee, 2004). Además, la Iniciativa para la Democracia y la Gobernanza Políitca y la Iniciativa para la Gobernanza Económica y Empresarial del NEPAD han sido tomadas como punto de partida para enfatizar políticas de buen gobierno desde las IFls y el G8 en sus planes para el continente africano.

La deuda de los países africanos ha supuesto un obstáculo fundamental para el desarrollo de sus economías. En 1996, el FMl y el BM impulsaron la Iniciativa para los países pobres altamente endeudados ${ }^{19}$ (HIPC, por sus siglas en inglés), siendo la mayoría países africanos, con el objetivo de aliviar la deuda hasta un nivel sostenible a los países más pobres. En 1999, la revisión de la iniciativa decidió acelerar el proceso y fortalecer los vínculos con la reducción de la pobreza y políticas sociales. En 2005, la iniciativa HIPC se suplementó con la Iniciativa de Alivia de la Deuda Multilateral (MDRI, por sus siglas en inglés), con el objetivo de acelerar el progreso de los Objetivos de Desarrollo del Milenio (ODM) y condonar hasta el 100 por cien de la deuda (FMl, 2021).

Con ocasión de las presidencias del Reino Unido del G8 y de la UE durante 2005, el gobierno británico creó la "Comisión para África", presidida por Tony Blair, con el objetivo de generar sinergias respecto a los esfuerzos por cambios en la política y la economía en África, y plantear nuevos enfoques para la relación de los donantes con África, incluyendo la necesidad de condonar totalmente la deuda multilateral de los países africanos (ODI, 2005).

En 2005, la propuesta británica de llegar a un acuerdo para aliviar la deuda africana se materializó en la Cumbre de jefes de Estado y de Gobierno del G8 celebrada en Gleneagles, donde las economías más importantes del planeta acordaron condonar la deuda multilateral ${ }^{20}$ de 18 de los países pobres altamente endeudados, y proseguir similares cancelaciones de la deuda para el resto del grupo de países HIPC. Además, los miembros del G8 se comprometieron a duplicar la ayuda al continente para 2010. Si el aumento de la ayuda para los países en vías de desarrollos sería de aproximadamente cincuenta mil millones de dólares al año, 25 mil millones estarían destinados a África (Blair, 2005).

\footnotetext{
19 Véase la lista de países e indicadores económicos en https://data.worldbank.org/country/XE

${ }^{20}$ Deuda contraída con tres instituciones multilaterales: El Banco Mundial, el Fondo Monetario Internacional y el Banco Africano de Desarrollo.
} 
No obstante, la condonación de la deuda está sujeta al cumplimiento de determinados criterios de condicionalidad política y económica formulados por las IFIs, como son los impuestos en los programas de ajuste estructural y los relativos al buen gobierno y la democratización. Es a este respecto donde han surgido más críticas a las iniciativas promovidas por el G8 y las IFIs, dada la injerencia en la formulación de las políticas públicas y la obligación de liberalización. Estas críticas son similares a las que vimos en relación con los Programas de Ajuste Estructural, y hacen temer que no se consiga alcanzar el objetivo de reducción de la pobreza.

La Unión Africana ha promovido, en la última década, una visión del desarrollo africano diferente de los presupuestos del ajuste estructural, con la aspiración de conseguir la transformación estructural de las economías africanas, a partir de la diversificación, la producción manufacturera e industrialización, y un crecimiento inclusivo y sostenible, plasmados en la Agenda 2063 (Unión Africana, 2015). Los presupuestos de la Agenda 2063, y sus objetivos, remiten a las aspiraciones del panafricanismo y a los primeros planes de desarrollo económico estructural en la primera década después de las independencias. En la actualidad, se trata de reposicionar África en la escena internacional y conseguir, en el periodo 2013-2063, una transformación real hacia el desarrollo sostenible y la integración regional y continental.

En este contexto, una de las iniciativas más recientes de la Unión Africana es el establecimiento en marzo de 2018 del Área de Libre Comercio Continental Africana (AcFTA, por sus siglas en inglés), a la que se han adherido todos los países africanos menos Eritrea, y que ha entrado en vigor desde enero de 2021. Su puesta en funcionamiento puede conllevar la superación del marco de las Comunidades Económicas Regionales (CER), los ocho grupos de integración regional en África. ${ }^{21}$ En estos grupos se han generado muchos solapamientos, al pertenecer los países a dos o más de las CER simultáneamente, generando descoordinación entre las organizaciones (Bidaurratzaga y Colom, 2005).

El objetivo principal del AcFTA es

\footnotetext{
${ }^{21}$ La UA reconoce ocho CERs, iniciativas de integración regional de diversa naturaleza y características. Sus nombres y siglas en inglés son los siguientes: Arab Maghreb Union (UMA), Common Market for Eastern and Southern Africa (COMESA), Community of Sahel-Saharan States (CEN-SAD), East African Community (EAC), Economic Community of Central African States (ECCAS), Economic Community of West African States (ECOWAS), Intergovernmental Authority on Development (IGAD)2, Southern African Development Community (SADC). Véase: Regional Economic Communities (RECs), https:// au.int/en/organs/recs
} 
la creación de un mercado continental único de bienes y servicios, con libre circulación de personas, de negocios e inversiones, y así preparar el camino para acelerar el establecimiento de la Unión Aduanera Continental y la Unión Aduanera Africana,

además de ampliar el comercio intraafricano, acelerar los procesos de integración regional y continental, y mejorar la competitividad de la industria y las empresas (Unión Africana, 2018).

Pese al optimismo generado por la constitución del AcFTA, y sus potenciales beneficios para el continente existen también obstáculos para su implementación que pueden limitar los objetivos de este gran proyecto. Algunos de ellos pasan por la negociación de adecuadas reglas de origen entre los países, la armonización de los solapamientos que existen entre las ocho CER, y el desafío que supone el déficit de infraestructuras en la mayoría de los países africanos (Bidaurratzaga Aurre et al, 2021)

\section{Rivalidad entre potencias por la influencia en África}

El último punto de nuestro análisis va a evidenciar la progresiva y creciente competición de las principales potencias por los recursos e influencia en el continente africano.

La creciente implicación de China en el continente ha suscitado acalorados debates entre los políticos y académicos, polarizados en dos posiciones opuestas, quienes consideran que el rol de China constituye una forma de explotación y neocolonialismo, con efectos negativos para el desarrollo de las sociedades africanas, y quienes ven en la acción china una oportunidad para el desarrollo global del continente.

El interés de china en los recursos naturales del continente es evidente, y constituye un aspecto prioritario en la política exterior china hacia África para garantizar la continuidad de su crecimiento económico. China ha conseguido erigirse en el primer socio inversor y comercial de muchos países africanos, ofreciendo también ayuda al desarrollo y cooperación militar.

Las respuestas de los países africanos a la expansión de China en el continente han sido variadas. En el caso de países con regímenes sancionados o aislados por la Comunidad internacional, como en el caso de Sudán o Zimbabue, los regímenes políticos africanos han acogido las iniciativas políticas y económicas chinas con los brazos abiertos para salir de su situación de ostracismo, convirtiendo a 
China en un socio estratégico y en una fuente de financiación. Las élites políticas de regímenes no democráticos se han mostrado más partidarias a la implicación china que los países con instituciones sólidas y economías desarrolladas, como en el caso de Sudáfrica, que ha frenado iniciativas chinas para evitar daños en las economías y negocios locales (Alden, 2007).

En la actualidad, la competición de las principales potencias por ganar influencia en el continente africano es una realidad. Las potencias occidentales se han implicado desde el final de la Guerra Fría con la nueva generación de gobiernos africanos, para incentivar la transformación de los países hacia la democracia y las economías de mercado, proveyendo apoyo financiero, además de iniciativas de alivio de la deuda en el marco del G8, para reducir la pobreza de los países menos desarrollados. El énfasis en la gobernanza y las condicionalidades políticas ha chocado frontalmente con la posición china de no intervención y de financiación sin condiciones, afectando a la agenda política de Occidente en África (Alden, 2007).

El reciente impulso de la acción de Rusia en África, junto con la expansión china en el continente, han provocado la alerta en Estados Unidos, y la voluntad de contrarrestar el papel de dichas potencias en África. La baja prioridad asignada a África en la política exterior de Estados Unidos, salvo en materia de lucha antiterrorista, ha resultado incongruente ya que el vacío americano en algunas esferas ha abierto la posibilidad de actuación en el continente a otras potencias mundiales, en un contexto geopolítico marcado por la competencia con China, tanto en términos económicos como de seguridad. Estos dos puntos estratégicos (seguridad y China) van a ser los ejes alrededor de los cuales se comience a perfilar una política africana a partir de la segunda mitad de la presidencia de Donald Trump, desatendiendo otros centros cruciales de interés como los programas de cooperación al desarrollo, la ayuda humanitaria, la promoción del buen gobiernoy la democracia, o las iniciativas de salud pública, entre otros programas y medidas que han inspirado las relaciones entre Estados Unidos y África tradicionalmente desde el final de la Guerra Fría (Alaminos Hervás, 2018).

Hay muchas voces que ven resonancias del pasado en el continente africano de hoy, y prevén una suerte de nueva Guerra Fría por el control de recursos estratégicos y zonas de influencia. Estas tensiones podrían conllevar inestabilidad e incluso nuevas guerras indirectas, consecuencia del choque de intereses de las principales potencias (Tafotie e Idahosa, 2016). En una visión más amable, la competición entre las potencias podría resultar en una acomodación de las distintas agendas políticas para garantizar la seguridad, generar beneficios mutuos y procurar la estabilidad regional (Gavin, 2021). 


\section{Conclusiones}

En términos generales, hay dos formas principales de proyectar nuestra mirada hacia el continente africano. Por un lado, una visión afropesimista, que identifica en el continente la proliferación de todos los males y problemas posibles para la humanidad, desde la guerra, el hambre y el subdesarrollo, hasta los efectos negativos del cambio climático, la corrupción y el mal gobierno. Por otro lado, la aproximación afrooptimista centra su atención en los aspectos positivos y las historias de éxito de África, desde el aumento significativo de la clase media y la juventud de la población, hasta los cambios políticos acontecidos en las últimas décadas y la expansión de múltiples movimientos sociales y activismos que buscan construir espacios políticos diferentes, desde el buen gobierno y el respeto de los derechos humanos.

África no puede seguir siendo representada como el continente de la tragedia, porque esa visión sesgada supone una simplificación de la singularidad de los países y la diversidad de las regiones del continente. Asimismo, tampoco podemos presentar una aproximación únicamente optimista o eufórica, que deje los elementos negativos o incómodos fuera de los análisis. En nuestra opinión, es fundamental analizar las dinámicas políticas, económicas y sociales de Africa desde la racionalidad y la observación de las realidades en el terreno, terminando con los mitos y prejuicios que suelen aparecer en cuanto leemos o escribimos sobre el continente.

En este artículo hemos abordado, de manera general y resumida, los últimos sesenta años del continente africano. Esta perspectiva a largo plazo nos permite observar las dinámicas políticas y económicas más relevantes para comprender el proceso de descolonización y el devenir del continente desde el momento de las independencias hasta nuestros días, con las problemáticas que subyacen a la construcción de los Estados-nación africanos y las distintas fases históricas que lo acompañan. Las problemáticas identificadas en el ámbito económico y político se deben a la conjunción de factores internos y externos.

En primer lugar, a nivel interno las mayores críticas se dirigen a los gobiernos poscoloniales de naturaleza neopatrimonial y los magros resultados de la ola democratizadora de los años noventa. La reciente multiplicación de movilizaciones sociales, protestas y revueltas en contra de las élites gobernantes muestra claramente el malestar social ante las situaciones de crisis económica y de mal gobierno, donde la acumulación de recursos políticos y económicos beneficia únicamente a una pequeña parte de la población. La magnitud y expansión de las protestas en muchos de los países africanos refleja la continuación de una larga tradición de 
movilización social y política en el seno africano, desde los movimientos de liberación nacional para terminar con el colonialismo, hasta la ola democratizadora de la década de los años noventa. El nuevo impulso de las movilizaciones populares a partir del nuevo milenio es sintomático de la fractura entre la sociedad civil y las clases gobernantes, generando un estallido social que busca construir un continente diferente, aunque los escenarios y resultados de las revueltas son heterogéneos.

En segundo lugar, la acción y la influencia de los actores externos en África ha sido constante, no sólo en el periodo colonial, sino en el periodo poscolonial. En gran medida, los intereses económicos y políticos de los actores internacionales han marcado la agenda de desarrollo africana. La especialización de las economías en el sector primario y en la exportación, la crisis de la deuda africana y los programas de ajuste estructural han tenido consecuencias muy negativas para los países africanos, tanto en el ámbito económico como en el social. Los obstáculos para el desarrollo económico de los países africanos no pueden explicarse únicamente aludiendo a la naturaleza de los gobiernos poscoloniales, sino teniendo en cuenta la influencia de los actores externos, que han promovido la explotación de los recursos en la era poscolonial, y se han beneficiado de términos asimétricos de intercambio comercial.

Aunque los indicadores macroeconómicos de los países africanos se sitúan entre los peores a nivel mundial, hay tendencias que incitan a la esperanza, como los intentos de diversificación de las economías para superar la dependencia de las exportaciones de materias primas, la inversión en infraestructura y el establecimiento de manufacturas locales. Asimismo, las iniciativas de alivio de la deuda para los países más endeudados han liberado a muchos Estados de una carga insostenible, y están mostrando su efecto en la reducción de la pobreza. No obstante, también han surgido críticas a estas iniciativas de alivio de la deuda al venir acompañadas de criterios de condicionalidad política y económica.

Para concluir, podemos afirmar que la clave para el desarrollo social y económico de África se encuentra en su sociedad civil. A lo largo de los sesenta años que han discurrido desde las independencias hasta la actualidad, las sociedades africanas han mostrado su resiliencia para resistir los distintos embates de los gobiernos poscoloniales, herederos de instituciones políticas débiles y no representativas, legadas por las potencias imperiales. Ante la urgencia de la construcción del Estado-nación y los desafíos económicos, los líderes políticos y héroes de las independencias eligieron un modelo unipartidista para dirigir los incipientes procesos de desarrollo. La evolución de las estructuras políticas ha conllevado la acumulación de los recursos políticos y económicos en manos de una élite estatal, dejando fuera a la 
mayoría de la población, y marginando a las regiones periféricas. No obstante, el contexto de los años noventa, con el final de la Guerra Fría, propició una ola democratizadora en África con un claro objetivo de generar espacios políticos participativos. La involución de ese proceso, y la respuesta represiva de las élites gubernamentales está siendo de nuevo desafiada desde principios del nuevo milenio, con movilizaciones multitudinarias que aspiran a generar Estados representativos y democráticos. Es un momento clave para África, un punto de inflexión hacia una eventual transformación política estructural, aunque tendremos que esperar para ver los resultados efectivos de este proceso a medio y largo plazo.

\section{Bibliografía}

AKE, C. (1976). Explanatory Notes on the Political Economy of Africa. The Journal of Modern African Studies, 14 (1), 1-23. http://www.jstor.org/stable/159645

- (1981). A Political Economy of Africa. Longman.

Alaminos Hervás, M. A. (2015). La política exterior y de seguridad de la Unión Europea hacia África Subsahariana: Estudio de caso de Sudán (1956-2011) e implicaciones para la política de la UE. [Tesis doctoral, Universidad Complutense de Madrid].

- (2018). "El impacto de la Administración Trump en las relaciones entre Estados Unidos y África: Evaluación temprana de cambios, continuidades y consecuencias". Revista UNISCI, 48, 369-400. DOI: http://dx.doi.org/10.31439/UNISCI-25

- (2019). "El levantamiento popular en Sudán (2018-2019): La lucha pacífica por la transformación política sudanesa", Documento de Trabajo Opex 98, 1-42, Fundación Alternativas.

AlDEN, C. (2007). China in Africa, Zed Books.

Alden, C., Alao, A., Chun, Z. y Barber, L. (eds.) (2018). China and Africa: Building Peace and Security Cooperation on the Continent, Palgrave.

All-African People's Conferences (1962). International Organization, 16(2), 429434. doi:10.1017/S0020818300011164.

AsANTE, M. K. (2007). The History of Africa: the Questfor Eternal Harmony, Routledge. 
BACH, D. C. (2016). Regionalism in Africa: Genealogies, Institutions and Trans-state Networks. Routledge.

BADIE, B. (1992). L'État importé: Essai sur l'occidentalisation de l'ordre politique. Arthème Fayard.

Banco Mundial (1981). Accelerated Development in Sub-Saharan Africa: An Agenda for Action (The Berg Report), The World Bank.

- (1994). Adjustment in Africa: Reforms, Results and the Road Ahead, Oxford University Press.

BAtES, R. H. (1981). Markets and States in Sub-Saharan Africa, University of California Press.

BAYART, J. F. (1989). L'État en Afrique. La politique du ventre, Arthème Fayard.

Bidaurratzaga, E. y Colom, A. (2005). "Regionalismo y estrategias de desarrollo en África: Implicaciones y retos del acuerdo de Cotonú y del Nepad". Revista de Economía Mundial 12, 89-121.

BidaurRatZAGA, E., Colom, A. y Marín, A. (2021). Integración y transformación económica en África: potencial y limitaciones del Área de Libre Comercio Continental Africana. Iberoamerican Journal of Development Studies, 10(1), 216-239. DOI: 10.26754/ojs_ried/ijds.565.

BlalR, T. (2005). "Chair's Summary. G8 Gleneagles Summit" (8 julio), final press conference. http://www.g8.utoronto.ca/summit/2005gleneagles/summary.html

BROWN, M. B. (2018) [1997]. Africa's Choices: After Thirty Years of the World Bank, Routledge.

Carbone, G. M. (2007). "Political Parties and Party Systems in Africa: Themes and Research Perspectives", World Political Science 3 (3), 1-29. https://doi. org/10.2202/1935-6226.1023

Chabal, P. y Daloz, J. P. (1999). Africa Works: Disorder as Political Instrument, Indiana University Press.

Cheeseman, N. (2015). Democracy in Africa: Successes, Failures and the Struggle for Political Reform, Cambridge University Press. 
Cheru, F. (1990). The Silent Revolution in Africa: Debt, Development and Democracy, Zed Books.

- (1999). Effects of Structural Adjustment Policies on the Full Enjoyment of Human Rights, United Nations.

Clapham, C. (1993). "Democratisation in Africa: Obstacles and Prospects", Third World Quarterly 14(3), 423-438. https://doi.org/10.1080/01436599308420335

- (1996). Africa and the International System: The Politics of State Survival, Cambridge University Press.

Comer, P. (2008). The Bottom Billion: Why the Poorest Countries Are Failing and What Can Be Done About It. Oxford University Press.

COLOM JAÉN, A. (2007). África en la economía mundial: Del imperialismo al Ajuste Estructural y más allá. En Martínez Peinado, J y Sánchez Tabarés, R. (Eds.). El futuro imposible del capitalismo (pp. 253-278). Icaria.

Cooper, F. (2002). Africa Since 1940: The Past of the Present. Cambridge University Press.

- (2005). Colonialism in Question: Theory, Knowledge, History. University of California Press.

Coquery-VIDrovitch, C. (2005). The History of African Cities South of the Sahara: From the Origins to Colonization. Wiener.

DAVIDSON, B. (1998). West Africa Before the Colonial Era: a History to 1850. Longman.

DUNNE, J.P. (2015, 2 febrero). 'Order at sea' and landlocked countries in Africa. Stockholm International Peace Research Institute [SIPRI]. https://www.sipri.org/ commentary/blog/2015/order-sea-and-landlocked-countries-africa

Ehret, C. (2002). The Civilizations of Africa: A History to 1800. University of Virginia Press.

Englebert, P. y Hummel, R. (2005). Let's Stick Together: Understanding Africa's Secessionist Deficit. African Affairs, 104 (416), pp. 399-427. doi:10.1093/ afraf/adi008 
Fondo Monetario Internacional (2021). Factsheet: Debt Relief Under the Heavily Indebted Poor Countries (HIPC) Initiative (23 marzo). https:// www.imf.org/en/About/Factsheets/Sheets/2016/08/01/16/11/ Debt-Relief-Under-the-Heavily-Indebted-Poor-Countries-Initiative

GAVIN, M. D. (2021). Major Power Rivalry in Africa. Council on Foreign Relations, Discussion Paper Series on Managing Global Disorder 5 (May). https://www.cfr. org/report/major-power-rivalry-africa

Gavshon, A. (1981). Crisis in Africa: Battleground of East and West. Penguin.

GeLLNER, E. (1983). Nations and Nationalisms. Blackwell.

GrifFIN, K. (1991). Foreign Aid after the Cold War. Development and Change, 22 (4), pp. 645-685. https://doi.org/10.1111/j.1467-7660.1991.tb00430.x

GRIFITHS, I. LI. (1995). The African Inheritance. Routledge.

HeRBST, J. (1992). Challenges to African Boundaries. Journal of International Affairs, 46 (1), pp.17-30. https://www.jstor.org/stable/24384114

- (2000). States and Power in Africa: Comparative Lessons in Authority and Control. Princeton University Press.

Hobsbawm, E. (1990). Nations and Nationalism since 1780: Programme, Myth, Reality. Oxford University Press.

Hoffmann, C. (2008). The Balkanization of Ottoman Rule: Premodern Origins of the Modern International System in Southeastern Europe. Cooperation and Conflict, 43 (4), pp. 373-396. https://www.jstor.org/stable/45084535

Holland, M. (2002), The European Union and the Third World. Palgrave.

IHONVBERE, J. O. (1996). Where Is the Third Wave? A Critical Evaluation of Africa's Non-Transition to Democracy. Africa Today, 43 (4), pp. 343-367. https://www. jstor.org/stable/4187120

Jackson, R. H. y Rosberg, C. G. (1982). Personal Rule in Black Africa: Prince, Autocrat, Prophet, Tyrant. University of California Press. 
JACQUEMOT, P. (2020). De l'élection à la démocratie en Afrique (1960-2020). Éditions Fondation Jean-Jaurès.

KaJeE, A. (2004). Nepad's APRM: A Progress Report, Practical Limitations and Challenges. En SA Yearbook of International Affairs, 2003/04 (pp.243-258). SAllA.

KanBUR, R. (2002). The New Partnership for Africa's Development (NEPAD): An Initial Commentary. Working Paper 127267. Cornell University. https://ecommons. cornell.edu/handle/1813/57913

KelleR, E.J. y RothCHIL, D. (eds.) (1996). Africa in the New International Order: Rethinking State Sovereignty and Regional Security. Lynne Rienner.

Mamdani, M. (1996). Citizen and Subject: Contemporary Africa and the Legacy of Late Colonialism. Princeton University Press.

MBEMBE, A. (2000). "At the Edge of the World: Boundaries, Territoriality, and Sovereignty in Africa", Public Culture, 12 (1), 259-284. https://doi. org/10.1215/08992363-12-1-259

MÉDARD, J. F. (1991). L'Etat néo-patrimonial en Afrique, Karthala.

- (1992). "Le "Big man" en Afrique: Esquisse d'analyse du politicien entrepreneur", L'Année sociologique, 42, 167-192. https://www.jstor.org/stable/27890139

NACIONES UnIDAS (s.f.). Estados de África. Departamento de la Asamblea General y de Gestión de Conferencias de Naciones Unidas. Consultado el 26 de julio de 2021. https://www.un.org/dgacm/es/content/regional-groups

- (s.f.). List of Landlocked Developing Countries. United Nations Conference on Trade and Development [UNCTAD]. Consultado el 27 de julio de 2021. https:// unctad.org/topic/landlocked-developing-countries/list-of-LLDCs

- (s.f.). Least Developed Countries. United Nations Office of the High Representative for the Least Developed Countries, Landlocked Developing Countries and the Small Island Developing States [UN-OHRLLS]. Consultado el 27 de julio de 2021. http://unohrlls.org/about-ldcs/

- (s.f.). Least Developed Countries. UNCTAD. Consultado el 27 de julio de 2021. https://unctad.org/topic/least-developed-countries 
- (s.f.) Least Developed Countries: Identification Criteria and Indicators. Department of Economic and Social Affairs. Consultado el 27 de julio de 2021. https://www. un.org/development/desa/dpad/least-developed-country-category/ldc-criteria. $\mathrm{html}$

Neuberger, B. (1976). The African Concept of Balkanisation. The Journal of Modern African Studies 14 (3), 523-529. https://www.jstor.org/stable/159750

Nkrumah, K. (2007) [1963]. Africa Must Unite, Panaf Books.

- (1966) [1965]. Neo-Colonialism: The Last Stage of Imperialism. International Publishers Co.

ODI (2005). The Commission for Africa Report and the UK Response to It (17 marzo). https://odi.org/en/events/the-commission-for-africa-report-and-the-ukresponse-to-it/

Organización de la Unidad Africana [OUA] (1963). Carta de la Organización de la Unidad Africana. https://www.usc.es/export9/sites/webinstitucional/gl/institutos/ ceso/descargas/OUA_Carta_1963_es.pdf

OUA (1964). Border Disputes Among African States. AHG/Res. 16(1), en OUA SECRETARIAT, Resolutions Adopted by the First Ordinary Session of the Assembly of Heads of State and Government Held in Cairo, UAR, from 17 to 21 July. hitps:// au.int/sites/default/files/decisions/9514-1964_ahg_res_1-24_i_e.pdf

Phillipson, D. W (1993). African Archaeology, $2^{a}$ ed. Cambridge University Press.

RODNEY, W. (1972). How Europe Underdeveloped Africa. East African Educational Publishers.

RosenBerg, E. S. (1985). "The Invisible Protectorate: The United States, Liberia, and the Evolution of Neocolonialism, 1909-40", Diplomatic History 9 (3), 191-21 4. https://doi.org/10.1111/j.1467-7709.1985.tb00532.x

Seger, W. (2018). The "Independence" of Ethiopia and Liberia. Africana Studies Student Research Conference. https://scholarworks.bgsu.edu/ africana_studies_conf/2018/007/2

SPEARS, I. (2004). Debating Secession and the Recognition of New States in Africa. African Security Review, 13(2), pp. 35-48. DOI: 10.1080/10246029.2004.9627283 
'T HART, M. C. (2016). "Why was Ethiopia not colonized during the late-nineteenth century 'Scramble for Africa'?", en J. BATEN (Ed.), A History of the Global Economy: From 1500 to the Present, 351-352, Cambridge University Press.

Tafotie, J. R. e Idahosa, S. O. (2016). Conflicts in Africa and Major Powers: Proxy Wars, Zone of Influence, or Provocating Instability. Vestnik RUDN, 16 (3), pp. 451460. http://journals.rudn.ru/international-relations/article/view/14763

TAYLOR, I. (2009). China's New Role in Africa. Lynne Rienner.

TiвEBU, T. (1996). Ethiopia: The "Anomaly" and "Paradox" of Africa. Journal of Black Studies, 26 (4), 414-430. https://doi.org/10.1177/002193479602600403

Touval, S. (1972). The Boundary Politics of Independent Africa, Harvard University Press.

United Nations. Economic Commission for Africa (1990). African Alternative Framework to Structural Adjustment Programmes for Socio-Economic Recovery and Transformation (AAF-SAP). https://hdl.handle.net/10855/5670"

Unión AfrICANA (s.f.). New Partnership For Africa's Development (NEPAD). Consultado el 31 de julio de 2021. https://au.int/en/organs/nepad

- (2015). Agenda 2063: The Africa we want (Popular version). African Union Commission.

- (2018). Agreement Establishing the African Continental Free Trade Area. African Union. https://au.int/en/ti/cfta/about

Westad, O. A. (2005). The Global Cold War, Cambridge University Press.

Wiseman, J. A. (1996). The New Struggle for Democracy in Africa, Avebury.

YEROS, P. (ed.) (1999). Ethnicity and Nationalism in Africa: Constructivist Reflections and Contemporary Politics, Palgrave.

Young, C. (1985). "African relations with the major powers", en G. M. CARTeR y P. O'Meara (Eds.), African Independence: The First Twenty-five Years, Indiana University Press. 
- (1986). "Africa's Colonial Legacy", en R. J. BERG y J. S. WHITAKER (Eds.), Strategies for African Development: A Study for the Committee on African Development Strategies, 25-51, University of California Press.

- (1994). The African Colonial State in Comparative Perspective, Yale University Press.

- (1994b). "Evolving modes of consciousness and ideology: nationalism and ethnicity", en D. E. APTer y C. G. ROSBERg (Eds.), Political Development and the New Realism in Sub-Saharan Africa, 61-86, University Press of Virginia.

- (1995). "The Heritage of Colonialism", en J. W. Harbeson y D. RothCHILD (Eds.), Africa in World Politics: Post-War Challenges, 23-30, Westview Press.

- (2012). The Postcolonial State in Africa: Fifty Years of Independence, 1960-2010. University of Wisconsin. 